Portland State University

PDXScholar

Engineering and Technology Management

Faculty Publications and Presentations

2019

\title{
Evaluating the Selection of Cellular Business Using a Hierarchical Decision Model: The Case of Libya
}

\author{
Maoloud Dabab \\ Portland State University \\ Rafaa Ibrahim Khalifa \\ Portland State University, rafaa.khalifa@gmail.com \\ Nader Beltaif \\ Portland State University
}

Follow this and additional works at: https://pdxscholar.library.pdx.edu/etm_fac

Part of the Business Commons

Let us know how access to this document benefits you.

\section{Citation Details}

M. Dabab, R. Khalifa and N. Beltaif, "Evaluating the Selection of Cellular Business Using a Hierarchical Decision Model: The Case of Libya," 2019 Portland International Conference on Management of Engineering and Technology (PICMET), Portland, OR, USA, 2019, pp. 1-9.

This Article is brought to you for free and open access. It has been accepted for inclusion in Engineering and Technology Management Faculty Publications and Presentations by an authorized administrator of PDXScholar. Please contact us if we can make this document more accessible: pdxscholar@pdx.edu. 


\title{
Evaluating the Selection of Cellular Business Using A Hierarchical Decision Model: The Case of Libya
}

\author{
Maoloud Dabab ${ }^{1}$, Rafaa Khalifa ${ }^{1}$, Nader Beltaif ${ }^{2}$ \\ ${ }^{1}$ Dept. of Engineering and Technology Management, Portland State University, Portland, OR - USA \\ ${ }^{2}$ Almadar Aljadid mobile phone company, Tripoli, Libya
}

\begin{abstract}
With all of the changes and challenges in Libya, the country possesses many positive attributes for carefully targeted investment in several sectors and seeks to use the last updated technology to improve public service. The Libyan ministry of telecommunication is interested in long-term investment in the cellular telecom industry. Although the ministry and its national operators have sought to catch up to the fast growth of the technology and provide the best service to the customers, the sector needs some reforms. Therefore, to improve prospects for success, four options (privatization of the companies, licensing a new foreign operator, supporting existing operators, and joint venture) were identified and evaluated based on a multiple perspectives criteria and goals using a Hierarchical Decision Model (HDM) methodology. The judgments of Libyan experts in the telecom sector were used to validate and quantify the model. The final result shows the licensing of a new foreign operator is considered to be the best option in the case of Libya.
\end{abstract}

\section{INTRODUCTION}

Due to rapid and discontinuous changes in telecom technology, market demand, future-focused enterprises, and Libyan circumstances, the Libyan Ministry of Telecommunication needs to increase the organizational responsiveness of the telecom sector through redesign and developing the existing companies, while also implementing innovative strategies and processes. In rapidly changing environments, it is critical to have a successful strategic management that is built on right planning and robust decisionmaking process [44]. Therefore, there are many alternatives including adapting, integrating, and re-configuring cellular telecom infrastructures.

Libya has two local operators, Almadar Aljadid and Libyana mobile phone companies, which are managed by Libyan Post Telecommunications \& Information Technology Company (LPTIC) under the Libyan Ministry of Telecommunication. The Libyan Post Telecommunications \& Information Technology Company (LPTIC) was established in 2005 as a holding company to the owner of major communications companies in Libya [28]. The purpose of creating LPTIC was to make an investment in telecommunications infrastructure in the country and abroad to support the development of the new Libya telecom and information technology services based economy, and to meet customer needs.

Almadar Aljadid was established in 1995 as the first mobile operator in Libya and North Africa. It has over three million subscribers including government establishments, businesses, and individuals, and is well-known for its high-quality services [29]. On the other hand, Libyana started its first mobile services in September 2004, and quickly achieved success in the market. It had more than 6.2 million subscribers in the first four years, which about $116 \%$ of the Libyan population [30].

Thus, Libya recently tried the phenomenon of the mobile virtual network operator, where the two providers, Libyan and Almadar, lease their network and sell minutes of communication to the third-party providers. However, these third-party companies are under the same Libyan Ministry of Telecommunication who own the telecom services, LTT Aljeal Aljadid, but they do not have their own networks. This experience was not successful. Therefore, we adopt a completely different point of view, and we focus on making suggestions with other alternatives to enhance the mobile telecom sector using one of the tools that can be used for decision analysis problems with multiple alternatives. This model helps to simplify complex decision problems, and to choose the best available alternative. For this reason, we applied The Hierarchical Decision Modeling (HDM) to assess the four choices for the Libyan Ministry of Telecommunication.

HDM is one of methods for formulating and analyzing decisions, using four steps: structuring of the situation into a hierarchical model; making pairwise comparisons and obtaining the judgmental matrix; relating weights and consistency of comparisons; and collecting the weights across various levels to achieve the final weights of alternatives.

The paper is organized as follows: The second section covers the literature review including an overview of the Libyan mobile telecom industry, and the history of multiple criteria ddecision-making. Section three explains the used methodology and clarification of pairwise comparison and expert judgments. Section four interprets components of the model in the four levels. Section five has the experts' analysis for the model. The results are discussed in the sixth section. Finally, the conclusion and recommendation are listed in the last section.

\section{LITERATURE REVIEW}

\section{A. Multiple Criteria Decision}

Since the 1960s, Multiple Criteria Decision Analysis (MCDA) and Multiple Criteria Decision-Making (MCDM) have been active research areas. They have produced many theoretical and applied papers and books that have been used in 
a variety fields such as business management, government administration, engineering management, scientific management, and economics.

Opricovic and Tzeng identified the main steps of multicriteria decision making as: Establishing system evaluation criteria, generating alternatives, evaluating the alternatives in terms of the criteria, applying an appropriate multi-criteria analysis method, accepting the optimal alternative(s), and finally gathering new information for next iteration of the multi-criteria optimization [1]. Multi-criteria tools cannot replace the decision maker's preferences, but they can help to manage these preferences. To help practitioners find the best methods and models to solve the issue, multi-criteria tools can be valuable. The techniques can handle a variety of different and conflicting criteria for selecting, evaluating, assessing, and ranking among predetermined decision alternatives to help decision makers to solve the complex decision situations that involve multiple criteria. Several methodologies and algorithms have been proposed and developed in this field, and most of them are categorized into multiple-criteria decision analysis (MCDA) or multiple-criteria decision making (MCDM). Basically, the MCDA has three main types of decisions analysis: Choosing the best alternative, sorting the alternatives into groups, and ranking the alternatives from best to worst.

Thus, the MCDM was categorized and divided into another two groups: Multi-Objective Decision Making (MODM) and Multi-Attribute Decision Making (MADM) [2] [3]. MODM methods are used for many real-world decision problems that have more than one goal (objective), and they account for multiple goals that indicate promising future directions. On the other hand, Multi-Attribute Decision Making (MADM) techniques are approaches for evaluating multi-criteria simultaneously, and areused to determine the optimal alternative among several alternatives. Most of the ranked MADM's techniques rely on different normalization and upper/lower bounds to eliminate dimensional unit differences among the criteria.

\section{B. Libyan Mobile Telecom Industry}

Most of society's services depend heavily on the availability of cellular services [4] [5]. Additionally, the sustainable economic growth of developing countries is dependent on a sound infrastructure in the telecommunication sector [6] [7]. In most African countries, mobile telecom services have been provided by their governments[8]; therefore, the competition in this sector barely exists. However, the situation has been slowly changing, and the market is becoming more open to competition. As a result, it has become attractive to many giant companies. In a study [9] examined the importance of connectivity in economic development, and the authors found that there is a strong relationship between technologies in the telecom industry and economic growth. Therefore, they highlighted the concept of connectivity frontier analysis for assessing the level of connectivity of the telecommunication infrastructure network, especially its core components. Also, they emphasized the significance of the investment in the decisions of the telecommunications sector, which continues to support this study.
Another statistical study [8] found that mobile cellular has a significant impact on the economic development in African countries; more specifically how the mobile telecom services in Libya have had a considerable impact on other sectors. For instance, recently the new system that Almadar Aljadid launched, Sadad Mobile Payment, helps to solve the problem of a lack of financial liquidity in Libya [10] [29]. In fact, Libya was one of the countries that was on the top of the list regarding cellular services, and by the end of 2010, Libya's cellular penetration reached $172 \%$ compared to other African countries [11]. The telecommunications sector in Libya was controlled by the son of Libya's president for a long time, which made the Libya Cellular Competition Intensity Index have a very low index of $34.3 \%$ in 2010 [11]., Hence, the Libyan mobile telecom sector has developed and undergone a significant transformation because of the substantial government policy reforms after the revolution in 2011. Therefore, the two mobile operators, Almadar and Libyana, are impacted by these developments, and must be aware of these changes to stay in the market.

One of the most critical strategies for mobile operators is to ensure customer satisfaction, but the Libyan cellular providers face many challenges to provide acceptable services [12]. As a result, a study suggested that mobile network performance and Quality of Service (QoS) should be evaluated since most of the customers are looking for network performance and quality [13] [45]. Thus, since Libya was classified as an uppermiddle-income country[8], the mobile subscribers have been looking for the best services and quality of the cellular system. Additionally, the Libyan mobile telecom sector has undergone a significant process of transformation because of the significant government policy reforms after the revolution in 2011. Thus, one of the government's intentions is licensing a new cellular provider. This has made many global providers think about the Libyan market because the more the market increases and the number of providers rises, the more markets become more competitive.

\section{Methodology}

\section{A. Hierarchical Decision Model (HDM)}

HDM was introduced and developed by Kocaoglu [14] to help decision makers. HDM is a multi-criteria tool used to quantify and incorporate quantitative and qualitative judgments. Basically, in the method, the final decisions gained are based on the local contributions by evaluating the last ranking of alternatives [15]. The HDM methodology depends on three main steps: Hierarchical decision modeling, which includes objectives, criteria, and alternatives; the selection of an expert panel to make the pairwise comparison; and a research instrument to obtain reasonable and balanced results. In other words, the method needs four main processes including the development of definitions and qualitative relationships; having a dry run with the program management team; and selecting an expert panel and panel meetings to build the decision model [14]. The HDM approach is taken from the work from the Analytic Hierarchy Process Approach, and it has been used widely in multiple applications such as for determining the innovativeness of the company [16], for 
selecting target markets of healthcare device [17], for identifying the best alternatives to help the diffusion of teleconsultation in healthcare [18], for healthcare technology assessment [19], for product lifecycle management [20], for evaluating the effectiveness of energy policy [21], and also for daily life decisions such as choosing the most desirable car characteristics [22]. Also, some studies integrated other methods to fill the gaps in the HDM. For example, it was used with the Technology Acceptance Model to increase the successful adoption of the teleconsultation diffusion model [18], and with the Delphi method to measure the indicator evaluation for specific industries [46][16].

Hogaboam, Ragel, and Daim highlighted the significant actions that HMD provides in the analysis process starting with structuring the decision problem into levels, making the pairwise comparison to elicit decision maker's preferences, calculating the priorities of the objectives, and finally checking the consistency of the decision maker 's responses [19]. Recently, Abbas and Kocaoglu defined the acceptable limits of inconsistency, and established consistency thresholds with significant analyzing for inconsistency in the HDM [23]. Sheikha, Kima, and Kocaoglu highlighted some critical points that were gained with the process of building the model. Their study covered the implications of preferences, and how they became elements for comparison. These elements include comparing long-term and short-term objectives, developing objectives and decision elements within a non-threatening environment, and involving both strategic and operational perspectives [17]. Thus, they listed the advantages of HDM as it simplifies the complexity of decisions while maintaining the accuracy of capturing judgments, and acts as a guide in strategic planning, and provides opinions and a framework for decision trend and sensitivity analyses. Furthermore, Chen and Kocaoglu emphasized managing a sensitivity analysis (SA) for the HDM results to address the various contingencies [15]. The HDM method creates significant information in each level of comparison between the objectives, criteria, and alternatives including the inconsistency and disagreement among the experts, which validates the accuracy, and provides valuable insights into the experts' opinions to assess the importance of the results.

\section{B. Pairwise Comparison}

The initial work of Saaty addressed the scaling ratios that use the principal eigenvector of a positive pairwise comparison matrix to introduce the notion of a hierarchy for multiple criteria decision making [24]. This work was the first study to introduce the hierarchy as a useful tool for decomposing an extensive problem. The consideration of many criteria and goals makes it difficult for experts to select the appropriate option. Therefore, using the concept of pairwise comparison makes the process easier for them. The expert opinion divides the $100 \%$ between two components based on which one has more impact or influence on the thing that is to be judged or decided. HDM is a method of measurement using pairwise comparisons, and relies on the expert judgments of the decision maker to derive priority scales.

\section{Expert Judgments}

In many decision models, the knowledge of experts, who have experience in a particular area, is used to judge which option is the best [39]. The concept of Expert Judgments is widely used in various aspects of many applications, and reliance on expert judgments in a complex situation is an attractive option for best practice as it ensures realistic measurements. With the lack of data in some applications, the contribution of experts is significant for evaluating the elements in the decision model. However, the challenge with implementing this concept is to identify and select the right experts who have the right experience and knowledge. We discuss more on the experts in this model in Section 5.

\section{Model And Data}

This model consists of five levels: Mission, objectives, goals, strategies, and actions. From these levels, D. Kocaoglu came up with an abbreviation for this model called (MOGSA) by taking the first letter from each level. Each level of these levels has a specific function for each unique model, and a brief definition for each level is introduced below:

- Mission: What project are we in? What business do we interest in?

- Objectives: What criteria should we add in order to success in our project?

- Goals: What are the targets to reach in order to fulfill our objectives?

- Strategies: What pathways should we follow in order to meet our goals?

- Actions: What projects should we have in order to develop our strategies?

\section{A. Our HDM Model:}

Even though the original model has five levels, in this model we considered only four of them since we are building this model based on long term strategy. The four levels of the process are shown on Figure 1. As is shown in that model, we identified four phases:

a) Mission

\section{- Improving the telecom sector and cellular services}

As an important level in the hierarchical model, the main reason for this model is to enhance the telecom sector and cellular services in Libya. It will also help make the necessary changes that will fulfill the best alternative based on the clear objectives and goals. This mission is developed specifically to meet the unique needs of the Libyan cellular sector with the possible visions available for the improvement.

\section{b) Objectives}

They are ground perspectives and measurable areas to make the mission statement achievable. They refer to specific measurable results for the goals. In this model, we 
develop the four specific objectives, which are the criteria of evaluation. They are:

\section{- Technical}

Understanding today's cellular industry from the technical point of view is needed for a successful sector transformation. There are many technical features and functions that can influence change. It is critical to address the technical capability aspect to make the changes with all the possible challenges and issues for the implementation since the application is a high-tech sector.

- Social

Telecom technology is changing our lives in ways we did not envision, and, in fact, most of society's services depend heavily on the availability of cellular services [37][36]. Libya was classified as an uppermiddle-income country [31], and the number of mobile subscribers is around $169 \%$ of the total population [38]. As a result, the social point of view is an important reason for making changes in this sector.

\section{- Economic}

There is a direct connection between sustainable economic growth and infrastructure in the telecommunication sector in the developing countries [6] [7]. Libya's economy depends primarily upon revenues from oil and gas exports, but it struggled during the last a few years due to declining the petroleum market. At the same time, the rapid development of the telecommunications sector has brought the attention of economists as an important income of the country.

\section{- Political}

The Libyan mobile telecom sector has undergone a significant process of transformation because of significant the government policy reforms after 2011, and there have been many technology policies reform and regulation changes based on the political issues. However, the Libyan political situation is still going through an unstable stage, which is taken into account when making changes within any sectors. Making an effective picture of the political scenarios for the Libyan mobile telecom sector transformation is a significant process.

\section{c) Goals}

Saaty structured a decision problem as a hierarchy starting from the goal on the top, and a group of criteria that connect the goal to the list of alternatives [24]. The goals are the targets that will be considered in order to achieve the objectives within the mission. There are a variety of goals that can be taken into consideration, but we focus on three main goals:

\section{- Customer satisfaction}

After 2011, the two mobile operators, Almadar and Libyana, have had to go through significant developments, and have had to become aware of big changes to stay in the market. One of the most critical strategies for mobile operators is to ensure customer satisfaction. The critical point of maintaining customer satisfaction is mastering resource management and obtaining high cellular network performance [34]. Enhancing network performance and services quality is the most important step for mobile providers to achieve customer satisfaction, which is directly related to profitability. Christan and Emmanuel pointed out that the key to sustaining competitive advantages is connected strongly to customer satisfaction, and this relates to quality service delivery [35]. Thus, many studies have focused on comparing the companies either in the same country or different countries from the financial perspective, and others from the customer satisfaction point of view. However, there are many segments to break down to multiple factors that represent customer satisfaction.

\section{- Profit}

This goal is forced to make the changes in practices, and continually seeks ways to raise the profit as the first priority. Many companies get into a routine to make more money, which is to increase your profit margins and financially succeed in the business. Even though the Libyan economy relies heavily on the petroleum sector, the telecom sector is considered as one of the most significant income sources to the government. Therefore, there has been an effort to enhance this sector. Opportunities remain in the mobile telecom sector for the Libyan Ministry of Telecommunication to provide high-quality mobile communication services through the two providers and increasing the business profitability.

\section{- Technology}

The cellular industry was introduced in the early 1970s, and there has been a remarkable development in technology creation, revolution, and evolution over the past decade. The $2 \mathrm{G}$ was launched with a significantly improved wireless communication quality in the early 1990s, which was designed based on Circuit Switching (CS) and Packet Switching (PS). The GSM service has been used successfully and effectively for a long time, and in some developing countries is still heavily used. However, with the emphatic increase of data usage, many operations have moved to the next generations, $3 \mathrm{G}, 4 \mathrm{G}$, and $5 \mathrm{G}$, which focus more on the data. Adopting the last generation in this industry is important to the customers and the market. Therefore, most developing countries try to catch these changes and go through these developments to achieve the competitive advantage to stay in the market [31][32][33]. Thus, the future need for development will bring new challenges to mobile providers, which can be solved by adopting the new technology. 
Therefore, one of the targets to reach in order to fulfill our objectives is catching the technology.

\section{d) Actions}

This level considers the possible alternatives, which are the decisions, including adapting, integrating, and reconfiguring. The four alternatives to the current situation for the cellular sector in Libya are:

\section{- Privatization the companies:}

There was a prelude plan to submit a tender of privatization the local providers, but this tender has been put on hold [25]. The government will privatize one or both the national telecommunications operators, Almadar and Libyan, with the sale of a percentage of the companies to other private telecom companies or sell the stocks to holders. The privatization program has been applied in many cases of government companies to be private for effective implementation of investment and development, but it may lead to loss of control over the sector and drain an important source of profit for the country. Therefore, this step needs to set many standards in many respects for the privatization process. This option will ensure a significant pace of growth that leads to the emergence of improvements in the telecom sector, but there will need to be many changes and adjustments with sector policies in the transformation stage to maintain governance to ensure transparency, equity, and accountability.

\section{- Licensing a new foreign operator}

Libya had intended to award a third mobile license in 2013, which was abruptly canceled, yet this option still is discussed to increase the competitiveness in this sector [26]. Opportunities remain in the mobile sector even though market penetration is still relatively low since so far, the only two mobile networks still have many challenges to provide high services. Therefore, many of large providers are looking at potential investment in Libya [27]. Libya had planned to tender a management contract for LIPTIC, which is seen as a prelude to privatization by analysts, but this tender has been put on hold [25]. This option does not include a virtual network operator since it is just a provider of management services from the existing suppliers with the same technology and infrastructure, which will not add any value in the current services. The foreign- provider firms can add value in terms of new services and commercial. However, licensing a new provider requires a change in the frequency spectrum to handle the three providers, which will limit the flexibility of using the band to the providers. There might also be a need to add new mobile towers and radio radiation.

\section{- Support existing operators}

This option includes providing support to the existing two companies from the technical support side and offering all development facilitation. Both providers have a young local professional cadre, which do not have the authority to make the changes due to the previous government and sector policies. As we mentioned, all of the telecom infrastructure is owned by the LPTIC, providing the facilities such as necessary equipment and shared space will make the ability to develop easier. Also, since they are totally government owned, making the possible facilities in the procedures with other sectors to provide a suitable environment for development will also be easier. With all of these, the service performance, customer reliability, and robustness of the sector control can be accommodated in a short time. However, there is a high risk of not achieving an acceptable level of success.

\section{- Joint venture}

It is a business arrangement where the local mobile providers will party agree to pool their resources for the purpose of accomplishing specific operational and managerial tasks. These tasks can be any business activities such as business expansion, development of new products, or moving into new markets. The joint venture will have a percentage of profits or losses and costs associated with it. The length of this alternative will be as needed, which means once the local providers have enough experience and stable business with expandable services the venture will end. The advantages this alternative are: Business can build more quickly when there is a lack of capabilities, there is an increase in the technical expertise, there is the ability to access and establish new markets and distribution channels. However, it is a critical decision since this industry is sensitive, and it affects the security of the country. Also, it needs a qualified committee to choose the right joint venture, and set out the terms and conditions in the agreement. 


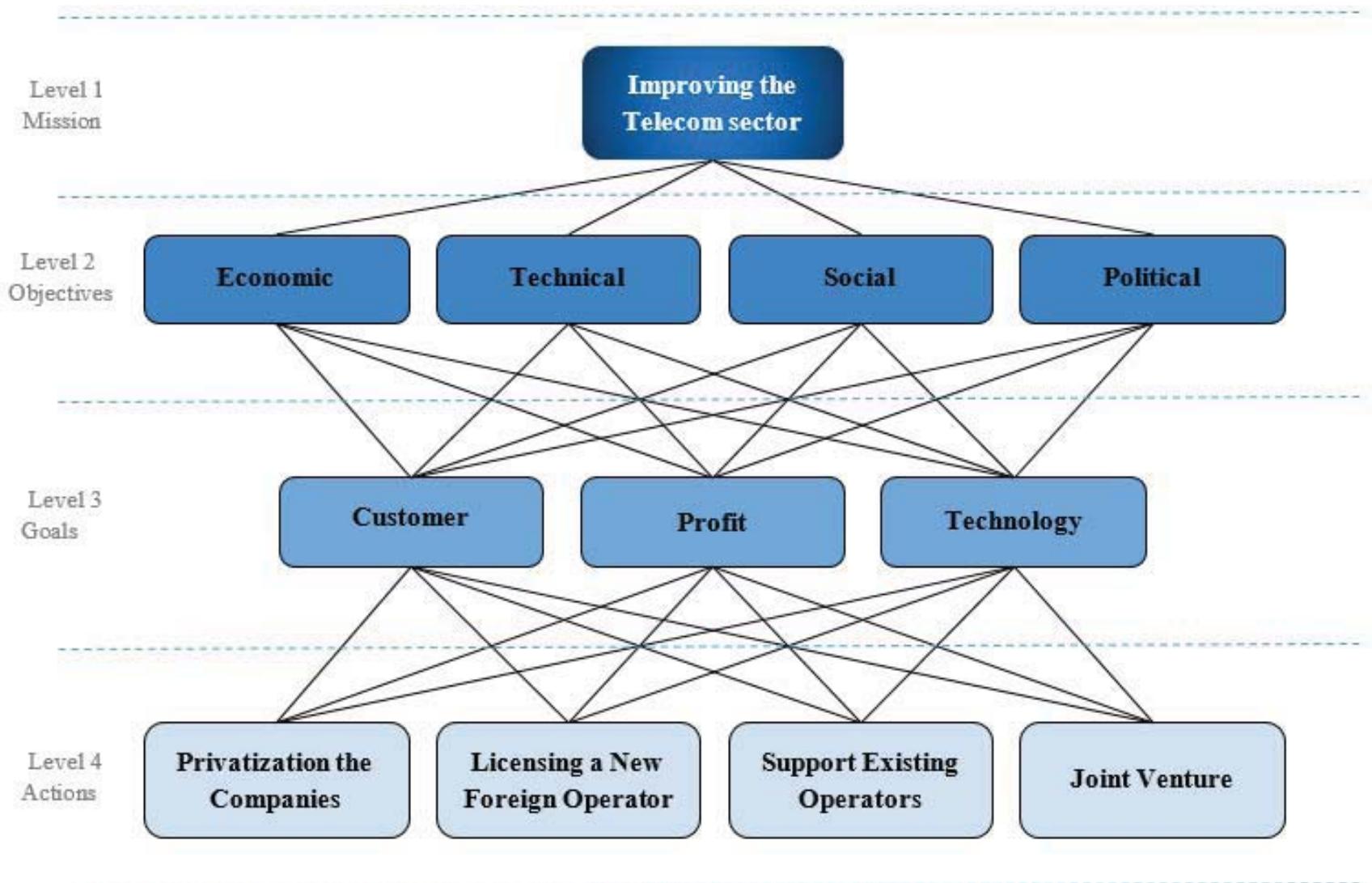

Fig. 1. The HDM Model

\section{RESULTS AND ANALYSIS}

The selection of experts is an essential and significant step in the expert judgments. Therefore, in this model, we considered the concept of consulting several experts to avoid the bias that may happen when the judgments are considered from a single expert. Ten experts, who are working on the top management level in Libyan Minister of Telecom, were invited and asked to submit their judgments on the decision model.
Tables I, II and III show the Level 2, 3, and 4 judgments respectively. The final results were usable and acceptable because the inconsistency measure was less than or close to (0.1) [41] [42] [43]. The social and economic perspective are ranked the most important with value of 0.29 among other perspectives with respect to the mission. The technical is ranked close with the first two perspective $(0.27)$, while political is ranked the last one $(0.16)$.

table I. Relative Value of the ObJectives (LeVel 2)

\begin{tabular}{|c|c|c|c|c|c|}
\hline & Economic & Technical & Social & Political & Inconsistency \\
\hline Expert 1 & 0.3 & 0.2 & 0.3 & 0.2 & 0 \\
\hline Expert 2 & 0.35 & 0.33 & 0.22 & 0.1 & 0.01 \\
\hline Expert 3 & 0.2 & 0.22 & 0.37 & 0.22 & 0.02 \\
\hline Expert 4 & 0.3 & 0.2 & 0.3 & 0.2 & 0 \\
\hline Expert 5 & 0.39 & 0.39 & 0.21 & 0 & 0.02 \\
\hline Expert 6 & 0.18 & 0.33 & 0.27 & 0.22 & 0 \\
\hline Expert 7 & 0.19 & 0.19 & 0.44 & 0.19 & 0 \\
\hline Expert 8 & 0.27 & 0.23 & 0.3 & 0.2 & 0 \\
\hline Expert 9 & 0.45 & 0.09 & 0.3 & 0.16 & 0.03 \\
\hline Expert 10 & 0.28 & 0.48 & 0.16 & 0.07 & 0.02 \\
\hline Mean & 0.29 & 0.27 & 0.29 & 0.16 & \\
\hline Minimum & 0.18 & 0.09 & 0.16 & 0 & \\
\hline Maximum & 0.45 & 0.48 & 0.44 & 0.22 & \\
\hline Standard Deviation & 0.09 & 0.11 & 0.08 & 0.07 & \\
\hline
\end{tabular}


TABLE II. Relative VAlue of The GoAls (LEVEL 3)

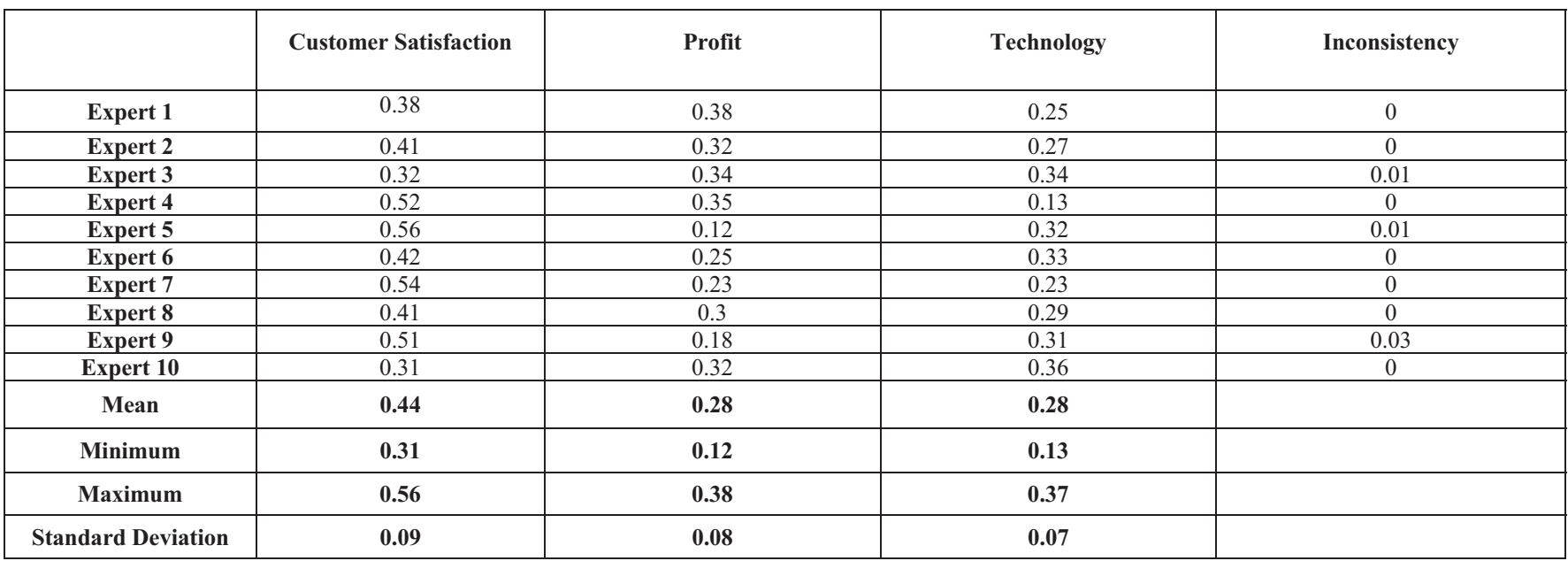

In Level 3, the customer satisfaction is ranked the highest relative importance with value of 0.44 among profit and technology that shared the same amount with value of 0.28 each. In Level 4, Licensing a New Foreign Operator is ranked the most important with value of 0.31 among others. The Joint Venture is the second most important choice with 0.27 , and it is better than the following option, Privatization the Companies, with difference value of 0.02. Support Existing Operators is ranked the least importance with value of 0.17 .

\section{DISCUSSION}

The model has four levels, and all the experts quantified all the levels in the model. After the all the responses have been collected from the experts, it is indicated that the importance of the social factor for Libya. At the same time, customer satisfaction seems to be the initial sweep as a main goal for improving the cellular telecom sector.
It is clear that the main drive to change is the need to make Libyans happier with the cellular services. According to the final result, the Ministry of Telecommunication should give a new license to a foreign operator as a solution to improve the cellular sector because it gets the highest mean value. The joint venture option might be a second choice to improve the cellular sector in Libya, where privatization and supporting the two existing operators are considered as last choices, third and fourth options, respectively.

This result is consist with the strategies in 2013 that the Libyan government was interested in awarding to a third mobile license [26]. However, this decision should be made by a set of preparations by local operators so as not to completely lose the competition with a new, larger operator. .. It is noteworthy that the data obtained from our panel of experts did not show a high disagreement value, and the disagreement value shown just (0.059), gives us a good indication that the experts' opinions about the decision were very close.

TABLE III. Relative VAlue of the Alterntives (LeVel 4)

\begin{tabular}{|c|c|c|c|c|c|}
\hline & $\begin{array}{l}\text { Privatization the } \\
\text { Companies }\end{array}$ & $\begin{array}{l}\text { Licensing a New } \\
\text { Foreign Operator }\end{array}$ & $\begin{array}{c}\text { Support Existing } \\
\text { Operators }\end{array}$ & Joint Venture & Inconsistency \\
\hline Expert 1 & 0.22 & 0.33 & 0.23 & 0.22 & 0 \\
\hline Expert 2 & 0.25 & 0.33 & 0.19 & 0.24 & 0 \\
\hline Expert 3 & 0.23 & 0.32 & 0.19 & 0.26 & 0.02 \\
\hline Expert 4 & 0.28 & 0.43 & 0.11 & 0.19 & 0 \\
\hline Expert 5 & 0.45 & 0.17 & 0.09 & 0.29 & 0.02 \\
\hline Expert 6 & 0.22 & 0.32 & 0.2 & 0.26 & 0 \\
\hline Expert 8 & 0.26 & 0.47 & 0.1 & 0.18 & 0.04 \\
\hline Expert 9 & 0.22 & 0.31 & 0.18 & 0.29 & 0 \\
\hline Expert 10 & 0.20 & 0.25 & 0.24 & 0.32 & 0.01 \\
\hline Mean & 0.25 & 0.31 & 0.17 & 0.27 & \\
\hline Minimum & 0.19 & 0.17 & 0.09 & 0.18 & \\
\hline Maximum & 0.45 & 0.47 & 0.24 & 0.43 & \\
\hline Standard Deviation & 0.07 & 0.09 & 0.05 & 0.07 & \\
\hline Disagreement & & & & & 0.059 \\
\hline
\end{tabular}


The advantage suggested by this low disagreement value is that there is little value in investing any further efforts to decrease the disagreement value more. Although the experts might have a little conflict of interest and ideas which lead to some issues such as disagreement, in this model we have low disagreement. In general, 0.1 or more in disagreement becomes an issue, and the authors should investigate the reasons behind the disagreement [40]. Thus, the bias and inconsistency value are acceptable overall, which means we do not have inconsistency in the fact or state of the judgment in the experts' quantifications.

\section{CONCLUSION AND RECOMMENDATION}

The remarkable diffusion of mobile services has outperformed, and the last 15 years have seen an unprecedented pace of telecommunications in the world. However, several developing countries still have many challenges to catch the improvements, so they have moved cautiously forward. Cellular telecom services are a significant part of the Libyan economy and social service, so the Libyan Ministry of Telecommunications sector should focus on the performance of operators, and to provide high cellular service and maintain the needs of the Libyan people. The two existing cellular operators are confronted with several challenges and issues that influence their transformational needs over years, which makes the situation more complicated for the high-level decision makers in the telecom sector to make the right decision for improvements.

The mission of improving and expanding the mobile telecom sector was accomplished by showing how the Libyan Ministry of Telecommunications sector could choose the best alternative solution by using a multi-criteria and goals model that is based on expert judgments. The main objective of this study is to build a model to simplify the situation of the mobile sector in Libya, and to provide a comprehensive decision model to the Libyan telecom management to improve its cellular infrastructure. The Hierarchical Decision Modeling (HDM) methodology was adopted, and ten expert judgments were used to evaluate the four suggested alternatives. While joint venture, privatization, and support for the existing operators are options of the reform process to improve the mobile telecom services in Libya, the new provider licensing is the best alternative, and it will prompt incumbent improvement in services and will reduce prices.

\section{ACKNOWLEDGMENTS}

The authors would like to thank the experts for their support in our research endeavors. Extended thanks also go out to all decision makers in the Libyan Ministry of Communications and Informatics. Finally, we are grateful to Prof. Adbdulgather Akki for his input in this research.

\section{REFERENCES}

[1] S. Opricovic and G.-H. Tzeng, "Compromise solution by MCDM methods: A comparative analysis of VIKOR and TOPSIS," Eur. J. Oper. Res., vol. 156, no. 2, pp. 445-455, Jul. 2004.

[2] J. Clímaco, Multicriteria analysis. Springer Verlag, 1997.
[3] J. Wallenius, J. S. Dyer, P. C. Fishburn, R. E. Steuer, S. Zionts, and K. Deb, "Multiple Criteria Decision Making, Multiattribute Utility Theory: Recent Accomplishments and What Lies Ahead," Manage. Sci., vol. 54, no. 7, pp. 1336-1349, Jul. 2008.

[4] D. F. Mojisola and K. Gbolahan, "Participatory Analysis of Cellular Network Quality of Service," International Journal of Computing \& ICT Research, vol. 9, no. 1, 2015.

[5] E. O. Oladeji, E. N. Onwuka, and M. A. Aibinu, "Determination of voice traffic busy hour and traffic forecasting in Global System of Mobile Communication (GSM) in Nigeria," in 2013 IEEE 11th Malaysia International Conference on Communications (MICC), pp. 184-189, 2013.

[6] F. N. Ugwoke and Others, "Using Software Engineering Approach in Mitigating QoS Challenges in Mobile Communication Networks in Nigeria," Computing, Information Systems, Development Informatics \& Allied Research Journal, vol. 5, no. 1, pp. 44-47, 2014.

[7] A. O. Ogunlewe, O. Shoewu, and N. T. Makanjuola, "QoS-Comparative Management and Evaluation of GSM Telephone System in Nigeria," The Pacific Journal of Science and Technology, vol. 17, no. 2, pp. 134-163, 2016

[8] H. K. Chavula, "Telecommunications development and economic growth in Africa," Information Technology for Development, vol. 19, no. 1, pp. 5-23, Jan. 2013.

[9] J. O. Prats Cabrera and J. A. Páez, "The Connectivity Frontier," InterAmerican Development Bank, IDB-WP-00899, Apr. 2018.

[10] A. Aljadid, "Almadar Aljadid 1st Mobile Operator In Libya." [Online]. Available: https://www.almadar.ly/en/Pages/Home.aspx. [Accessed: 13May-2018].

[11] J. Abbassi, "Information and Communication Technology in the Middle East: Situation as of 2010 and Perspectives Scenarios for 2030," Center for Social and Economic Research, 105, Oct. 2011.

[12] M. Dabab, "An Overview of Mobile Indoor Coverage: A Case Study of a Local Mobile Operator," Almadar Journal For Communications, Information Technology, And Applications, vol. 03, no. 01, pp. 31-36, April 2016.

[13] V. S. P. Kumar, B. Anuradha, and V. Naresh, "Improvement of Key Performance Indicators and QoS Evaluation in Operational GSM Network,” Int. J. Eng. Res. Appl., vol. 1, no. 3, pp. 411-417, 2002.

[14] D. F. Kocaoglu, "A participative approach to program evaluation," IEEE Trans. Eng. Manage., vol. EM-30, no. 3, pp. 112-118, Aug. 1983.

[15] H. Chen and D. F. Kocaoglu, "A sensitivity analysis algorithm for hierarchical decision models," Eur. J. Oper. Res., vol. 185, no. 1, pp. 266-288, Feb. 2008.

[16] K. Phan, "Decision-Making Tools: Innovation Measurement Framework," in Hierarchical Decision Modeling: Essays in Honor of Dundar F. Kocaoglu, T. U. Daim, Ed. Cham: Springer International Publishing, pp. 321-336, 2016.

[17] N. J. Sheikh, K. Kim, and D. F. Kocaoglu, "Use of hierarchical decision modeling to select target markets for a new personal healthcare device," Health Policy and Technology, vol. 5, no. 2, pp. 99-112, Jun. 2016.

[18] H. A. Alanazi, T. U. Daim, and D. F. Kocaoglu, "Identify the best alternatives to help the diffusion of teleconsultation by using the Hierarchical Decision Model (HDM)," Proceedings of PICMET'15: Management of the Technology Age, 2015.

[19] L. Hogaboam, B. Ragel, and T. Daim, "Development of a Hierarchical Decision Model (HDM) for health technology assessment (HTA) to design and implement a new patient care database for low back pain," in Proceedings of PICMET '14 Conference: Infrastructure and Service Integration, pp. 3511-3517, 2014.

[20] J. Eastham, D. J. Tucker, S. Varma, and S. M. Sutton, "PLM Software Selection Model for Project Management Using Hierarchical Decision Modeling With Criteria From PMBOK Knowledge Areas," Engineering Management Journal, vol. 26, no. 3, pp. 13-24, Sep. 2014.

[21] R. Abotah and T. U. Daim, "Towards building a multi perspective policy development framework for transition into renewable energy," Sustainable Energy Technologies and Assessments, vol. 21, pp. 67-88, Jun. 2017. 
[22] B. Saatchi, L. Pham, H. Pham, C. F. Pai, and Y. Tran, "Decision model for selecting a sedan car," in 2013 Proceedings of PICMET '13. Technology Management in the IT-Driven Services (PICMET), pp. 393 400, 2013.

[23] M. S. Abbas and D. F. Kocaoglu, "Consistency thresholds for Hierarchical Decision Model," in 2016 Portland International Conference on Management of Engineering and Technology (PICMET), pp. 566-575, 2016

[24] T. L. Saaty, "A scaling method for priorities in hierarchical structures," J. Math. Psychol., vol. 15, no. 3, pp. 234-281, June. 1977.

[25] "Kuwait's Zain Eyes Libyan Growth," Libya Business News, 28-Jun2013. [Online]. Available: https://www.libyabusinessnews.com/2013/06/28/kuwaits-zain-eyes-libyan-growth/. [Accessed: 09-Dec-2018].

[26] "Libya to Offer Third Mobile Licence," Libya Business News, 13-Sep2013. [Online] Available: https://www.libyabusinessnews.com/2013/09/13/libya-to-offer-third-mobile-licence/. [Accessed: 09-Dec-2018].

[27] “Kuwait's Zain Eyes Libyan Telco Market," Libya Business News, 09Apr-2013. [Online]. Available: https://www.libyabusinessnews.com/2013/04/09/kuwaits-zain-eyes-libyan-telco-market/. [Accessed: 09-Dec-2018].

[28] "Home," LPTIC. [Online]. Available: http://lptic.ly/en/. [Accessed: 09Dec-2018].

[29] "Almadar Aljadid 1st Mobile Operator In Libya," [Online]. Available: https://www.almadar.ly /en/Pages/Home.aspx. [Accessed: 09-Dec2018].

[30] "Libyana.The Biggest Mobile Operator in Libya," [Online]. Available: http://libyana.ly/en/. [Accessed: 09-Dec-2018].

[31] H. K. Chavula, "Telecommunications development and economic growth in Africa," Information Technology for Development, vol. 19 no. 1, pp. 5-23, 2012.

[32] M. Casey, "The Future of Telecoms in Africa," Deloitte \& Touche, 2014.

[33] N. N. Beltaif and C. Weber, "Using Game Theory in Libyan Cellular Market," 2018 Portland International Conference on Management of Engineering and Technology (PICMET), 2018.

[34] M. Dabab and T. Anderson, "Benchmarking Cellular Technical Efficiency Using Data Envelopment Analysis," American Society for Engineering Management, Coeur d'Alene, 2018.
[35] [35] A. Christan and E. E. Emmanuel, "An Assessment of Customer Satisfaction with GSM Service Quality in Cross River State, Nigeria," Journal of Marketing and Consumer Research, Vol.27, pp. 62-70, 2016.

[36] E. O. Oladeji, E. N. Onwuka, and M. A. Aibinu, "Determination of voice traffic busy hour and traffic forecasting in Global System of Mobile Communication (GSM) in Nigeria," 2013 IEEE 11th Malaysia International Conference on Communications (MICC), 2013.

[37] E. O. Oladeji, E. N. Onwuka, and M. A. Aibinu, "Participatory Analysis of Cellular Network Quality of Service," International Journal of Computing and ICT Research, Vol. 9, Issue 1, pp 25-40, 2015.

[38] S. Kemp, "Digital Data \& Trends for Every Country in the World," LinkedIn, 26-Jan-2017. [Online]. Available: https://www.linkedin.com/pulse/digital-data-trends-every-countryworld-simon-kemp/. [Accessed: 18-Dec-2018].

[39] B. Gastel, and R. A. Day, "How to write and publish a scientific paper. ABC-CLIO, 2016.

[40] M. Khanam, H. Barham, A. Nour, S. Thabet, and T. Daim, "Technology Assessment in the Energy Sector," In Research and Development Management, Springer, Cham, pp. 61-85, 2017.

[41] K. Phan, "Innovation Measurement: A Decision Framework to Determine Innovativeness of a Company, Dissertation," 2013.

[42] L. Chan, "Developing a Strategic Policy Choice Framework for Technological Innovation: Case of Chinese Pharmaceuticals, Dissertation," 2013.

[43] D. J. Weiss and J. Shanteau, "Empirical Assessment of Expertise," Hum. Factors J. Hum. Factors Ergon. Soc., vol. 45, no. 1, pp. 104-116, 2003.

[44] M. Dabab and C. Weber, "Business Intelligence and Data Analytics as a Driver of Dynamic Capability Strategic Approach," 2018 Portland International Conference on Management of Engineering and Technology (PICMET), 2018.

[45] S. O. Seytnazarov, "RF optimization issues in GSM networks," in 2010 4th International Conference on Application of Information and Communication Technologies, pp. 1-5, 2010.

[46] A. K. Puthanpura, R. Khalifa, and L. Chan. "Assessing emerging automotive technologies for the future." 2015 Portland International Conference on Management of Engineering and Technology (PICMET). IEEE, 2015. 